\title{
Partial penectomy or total penectomy for T1 and T2 squamous cell carcinoma of the penis?
}

\author{
Qi-Le Zheng ${ }^{1 *}$, Yu-Peng $\mathrm{Wu}^{2 *}$, Zi-Ping Zhang ${ }^{1}$, Ning $\mathrm{Xu}^{2}$ \\ ${ }^{1}$ Department of Dermatology, ${ }^{2}$ Department of Urology, First Affiliated Hospital of Fujian Medical University, Fuzhou 350005, China \\ Contributions: (I) Conception and design: ZP Zhang, N Xu; (II) Administrative support: None; (III) Provision of study materials or patients: None; (IV) \\ Collection and assembly of data: QL Zheng, YP Wu; (V) Data analysis and interpretation: QL Zheng, N Xu; (VI) Manuscript writing: All authors; (VII) \\ Final approval of manuscript: All authors. \\ "These authors contributed equally to this work. \\ Correspondence to: Ning Xu. Department of Urology, First Affiliated Hospital of Fujian Medical University, 20 Chazhong Road, Fuzhou 350005, \\ China. Email: drxun@fjmu.edu.cn.
}

\begin{abstract}
Background: To assess prognostic factors and survival outcomes for partial penectomy (PP) and total penectomy (TP) patients with T1 and T2 squamous cell carcinoma of the penis.

Methods: The Surveillance, Epidemiology, and End Results (SEER) database was used to identify 708 penile cancer patients. Among these, 607 underwent PP and 101 underwent TP. Kaplan-Meier analysis was used to compare survival outcomes between PP and TP patients. Univariate and multivariate Cox proportional hazards regression models were used to determine prognostic factors.

Results: There were significant differences in marital status and regional lymph node removal between patients of the PP and TP groups. Multivariate regression analysis demonstrated that age [odds ratio $(\mathrm{OR})=1.045 ; 95 \%$ confidence interval $(\mathrm{CI}): 1.034-1.057 ; \mathrm{P}<0.0001]$, T2 carcinoma $(\mathrm{OR}=1.388 ; 95 \% \mathrm{CI}$ : 1.077-1.788; $\mathrm{P}=0.0114)$, node stage $\mathrm{N} 1-3$ (OR $=3.351 ; 95 \% \mathrm{CI}: 2.317-4.847 ; \mathrm{P}<0.0001)$, and $\geq 4$ regional lymph nodes removed ( $\mathrm{OR}=0.498 ; 95 \% \mathrm{CI}: 0.255-0.972 ; \mathrm{P}=0.0411)$ were independent predictors of overall survival (OS). Age (OR =1.019; 95\% CI: 1.005-1.033; $\mathrm{P}=0.0065)$, stage N1-3 (OR =5.127; 95\% CI: 3.2138.181; $\mathrm{P}<0.0001)$, and $\geq 4$ regional lymph nodes removed $(\mathrm{OR}=0.452 ; 95 \% \mathrm{CI}: 0.219-0.932 ; \mathrm{P}=0.0315$ ) were independent predictors of cancer specific survival (CSS). However, there was no significant difference between PP and TP in terms of OS and CSS.

Conclusions: There was no significant difference in terms of OS and CSS between patients treated by PP or TP. T2 was associated with shorter OS, while age and N1-3 were associated with shorter OS and CSS. Removal of $\geq 4$ regional lymph nodes was associated with longer OS and CSS.
\end{abstract}

Keywords: Partial penectomy (PP); total penectomy (TP); squamous cell carcinoma

Submitted Apr 06, 2018. Accepted for publication Aug 05, 2019.

doi: $10.21037 /$ tcr.2019.08.37

View this article at: http://dx.doi.org/10.21037/tcr.2019.08.37

\section{Introduction}

Penile cancer is a rare disease with a high risk of recurrence in both regional lymph nodes and distant sites (1). It is estimated that 2,120 new individuals were diagnosed with penile cancer in 2017 (2). Because of the rarity of penile cancer, experience in the management of this disease is limited (3). The management of penile cancer therefore remains a significant challenge for urologists.
Currently, surgery remains the mainstay of treatment for penile cancer (4). The two surgical approaches for penile cancer are partial penectomy (PP) and total penectomy (TP). Although TP is associated with a low recurrence rate, it has a serious functional and psychological effect on patients. PP can also cause a series of problems for patients; difficulty in controlling urination as well as impaired sexual function remain a serious problem in a number of patients because of 
Table 1 Patients demographics and tumor characteristics stratified by surgery

\begin{tabular}{|c|c|c|c|}
\hline Surgery type & $\begin{array}{l}\text { Partial penectomy } \\
\qquad(\mathrm{N}=607)\end{array}$ & $\begin{array}{l}\text { Total penectomy } \\
\qquad(\mathrm{N}=101)\end{array}$ & $P$ value \\
\hline Year & $2009.395 \pm 3.082$ & $2009.089 \pm 3.299$ & 0.383 \\
\hline Age & $66.016 \pm 14.485$ & $64.495 \pm 13.769$ & 0.26 \\
\hline Follow-up & $40.974 \pm 34.069$ & $39.594 \pm 33.853$ & 0.676 \\
\hline Race & & & 0.576 \\
\hline Black & $50(8.237 \%)$ & $11(10.891 \%)$ & \\
\hline Other & $42(6.919 \%)$ & $5(4.950 \%)$ & \\
\hline White & $515(84.843 \%)$ & $85(84.158 \%)$ & \\
\hline Marital & & & 0.008 \\
\hline Unmarried & $206(33.937 \%)$ & $48(47.525 \%)$ & \\
\hline Married & $401(66.063 \%)$ & $53(52.475 \%)$ & \\
\hline pT stage & & & 0.057 \\
\hline pT1 & $350(57.661 \%)$ & $48(47.525 \%)$ & \\
\hline рT2 & 257 (42.339\%) & $53(52.475 \%)$ & \\
\hline $\mathrm{pN}$ stage & & & 0.673 \\
\hline pNO & 509 (83.855\%) & $83(82.178 \%)$ & \\
\hline pN1-3 & $98(16.145 \%)$ & $18(17.822 \%)$ & \\
\hline \multicolumn{2}{|c|}{ Regional lymph nodes removed } & & 0.023 \\
\hline 1 to 3 & $18(2.965 \%)$ & $2(1.980 \%)$ & \\
\hline 4 or more & $123(20.264 \%)$ & $33(32.673 \%)$ & \\
\hline None & $466(76.771 \%)$ & $66(65.347 \%)$ & \\
\hline
\end{tabular}

the extent of tissue removed.

The purpose of this study was to evaluate and compare overall survival (OS) and cancer specific survival (CSS) in patients treated with PP or TP for penile cancer utilizing the large population-based Surveillance, Epidemiology, and End Results (SEER) database.

\section{Methods}

\section{Ethical standards}

Information from the SEER database has been de-identified and informed consent is not required for its use.

\section{Patients}

A total of 1,060 eligible patients were identified according to the following inclusion criteria: year of diagnosis between 2004-2014, penile cancer as the first and only malignant cancer diagnosis, patient underwent PP or TP, and disease pathologically confirmed as squamous cell penile carcinoma. The $\mathrm{T}$ stage and $\mathrm{N}$ stage in this study were referred to pathological $\mathrm{T}(\mathrm{pT})$ stage and pathological $\mathrm{N}$ (pN) stage. The regional lymph node surgery described in this study referred to procedure of removal, biopsy and aspiration of regional lymph nodes performed during the initial work-up or first course of therapy. The pN0 stage in this study all referred to the situation that a "dissection" of a lymph node drainage area is found to contain no positive lymph nodes at the time of pathologic examination. Patients who were diagnosed at autopsy or at time of death, those pathologically confirmed as M1, and those with other first primary cancers were excluded. Follow-up times were calculated from January 1, 2004 to December 31, 2014.

\section{Statistical analysis}

The demographics and clinical characteristics of patients were compared between the PP and TP groups using the Chi-square test. Survival curves were generated using the Kaplan-Meier method, and the unadjusted OS and CSS were compared using the log-rank test. OS was defined as the time from the date of diagnosis of penile cancer to the date of death (irrespective of cause). CSS was defined as the time from the date of diagnosis of penile cancer to the date of death directly associated with the cancer. Cox proportional hazards regression models were used to calculate the adjusted hazard ratios (HRs), with $95 \%$ confidence intervals (CIs), for determining prognostic factors. Statistical analyses were performed using the $\mathrm{R}$ software package, version 3.4.1. A two-sided $\mathrm{P}$ value $<0.05$ was considered statistically significant.

\section{Results}

\section{Patient demographics and clinical characteristics}

We identified 708 patients included in the SEER database that had been diagnosed with penile cancer between 2004 2014. Among these patients, 607 (85.734\%) underwent PP and $101(14.266 \%)$ underwent TP. The mean follow-up times for the PP and TP groups were $40.974 \pm 34.069$ months and $39.594 \pm 33.853$ months, respectively. The patient demographics and tumor characteristics, stratified according to surgery type, are presented in Table 1 . 


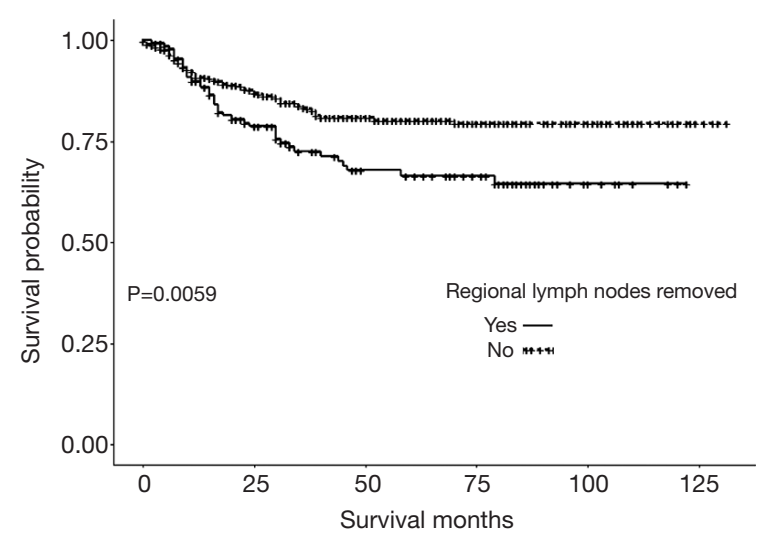

Figure 1 Cancer specific survival of patients who underwent partial penectomy for penile cancer stratified by regional lymph node removal status.

Differences in both marital status and regional lymph node removal were statistically significant between the two groups. The TP group had a lower proportion of married patients, when compared with the PP group (PP 66.063\% vs. TP $52.475 \% ; \mathrm{P}=0.008$; Table 1). The TP group also had more patients with four or more regional lymph nodes removed (PP 20.264\% vs. TP 32.673\%; $\mathrm{P}=0.023$; Table 1).

\section{Survival analysis}

The survival analyses of OS and CSS for the PP and TP groups were performed and the results demonstrated that there was no difference between PP and TP groups in terms of OS and CSS. Also, there was no difference between PP and TP groups in terms of OS and CSS in T1 subgroup patients and T2 subgroup patients, and also the node stage $\mathrm{N} 0$ and $\mathrm{N}+$ subgroups. We also analyzed OS and CSS in PP and TP groups stratified according to regional lymph node removal status. The results demonstrated that for those patients who underwent PP, there is a significant difference in CSS (Figure 1) between patients with regional lymph node removal and those did not undergo regional lymph node removal. However, for patients who underwent TP, there was no difference in OS and CSS between patients with regional lymph node removal and those did not undergo regional lymph node removal.

The multivariate regression analysis demonstrated that age [odds ratio $(\mathrm{OR})=1.045 ; 95 \%$ confidence interval (CI): 1.034-1.057; $\mathrm{P}<0.0001]$, T2 carcinoma $(\mathrm{OR}=1.388$; 95\% CI: 1.077-1.788; $\mathrm{P}=0.0114$ ), node stage $\mathrm{N} 1-3$ (OR $=3.351 ; 95 \%$ CI: $2.317-4.847 ; \mathrm{P}<0.0001$ ), and removal of $\geq 4$ regional lymph nodes (OR $=0.498$; 95\% CI: $0.255-0.972$; $\mathrm{P}=0.0411$ ) were independent predictors of OS. Age (OR $=1.019 ; 95 \%$ CI: $1.005-1.033 ; \mathrm{P}=0.0065)$, node stage $\mathrm{N} 1-3$ $(\mathrm{OR}=5.127 ; 95 \%$ CI: 3.213-8.181; $\mathrm{P}<0.0001)$, and removal of $\geq 4$ regional lymph nodes ( $\mathrm{OR}=0.452 ; 95 \%$ CI: 0.219 0.932; $\mathrm{P}=0.0315$ ) were also independent predictors of CSS. However, there were no significant differences in OS and CSS between the PP and TP patient groups (Table 2).

\section{Discussion}

In this study, we sought to identify the prognostic factors for OS and CSS in patients with penile cancer, by utilizing the SEER population-based database. This study demonstrated that patient demographics and tumor characteristics were quite different between the PP and TP groups. Prognostic factors for OS in penile cancer have been reported by Kamel et al. (5) to include age, Grade III status, positive lymph node status, a positive surgical margin, and a higher Charlson/Deyo comorbidity score. da Costa et al. (6) reported that lymphovascular invasion and lymph node ratio were independent predictors of CSS. Wen et al. (7) demonstrated that pathological lymph node metastasis was the independent prognostic factor for CSS. In this study, multivariate Cox regression analysis revealed that age, tumor stage, $\mathrm{N}$ stage, and regional lymph node removal status were independent predictors of OS. Multivariate Cox regression analysis also revealed that age, $\mathrm{N}$ stage, and regional lymph node removal status were independent predictors of CSS. However, multivariate Cox regression analysis demonstrated that surgery type was not an independent prognostic factor for either OS or CSS.

Predictors of poor OS in this study included age, T2 stage, and any $\mathrm{N}$ positive stage. Advanced age was reported to be a predictor of poor OS in a report based on the National Cancer Database (8). In this study, age was slightly associated with poor OS in penile cancer. Thuret et al. (9) reported that, for squamous cell carcinoma of the penis, unmarred men were more likely to be associated with unfavorable tumor stage and poor OS, when compared with their married counterparts. In this study, multivariate Cox regression analysis demonstrated that marital status was not associated with OS. It remains controversial whether or not race is associated with OS in patients with penile cancer. In this study, race was not associated with OS. However, Rippentrop et al. (10) reported that African-American men presented with a higher stage of disease and at a younger age. Conversely, Thuret et al. (9) reported that race was not 
Table 2 Univariate and multivariate Cox regression analysis of overall survival and cancer specific survival

\begin{tabular}{|c|c|c|c|c|}
\hline Variables & \multicolumn{2}{|c|}{ Overall survival } & \multicolumn{2}{|c|}{ Cancer specific survival } \\
\hline Age & $1.042(1.031,1.052) ;<0.0001$ & $1.045(1.034,1.057) ;<0.0001$ & 1.011 (0.998, 1.024); 0.0981 & 1.019 (1.005, 1.033); 0.0065 \\
\hline Year & $0.982(0.936,1.031) ; 0.4705$ & 0.975 (0.929, 1.024); 0.3134 & 0.955 (0.895, 1.019); 0.1682 & $0.953(0.894,1.016) ; 0.1423$ \\
\hline \multicolumn{5}{|l|}{ Race } \\
\hline Other & 1.037 (0.534, 2.011); 0.9155 & $0.926(0.472,1.817) ; 0.8235$ & $0.944(0.366,2.435) ; 0.9044$ & $0.792(0.303,2.069) ; 0.6345$ \\
\hline White & $1.212(0.774,1.896) ; 0.4012$ & $1.146(0.724,1.813) ; 0.5605$ & 1.167 (0.628, 2.168); 0.6254 & $1.114(0.587,2.113) ; 0.7414$ \\
\hline \multicolumn{5}{|l|}{ Marital } \\
\hline Unmarried & 1 & 1 & 1 & 1 \\
\hline $\mathrm{pT} 1$ & 1 & 1 & 1 & 1 \\
\hline pT2 & $1.493(1.167,1.909) ; 0.0014$ & $1.388(1.077,1.788) ; 0.0114$ & 1.753 (1.241, 2.477); 0.0014 & 1.396 (0.972, 2.005); 0.0707 \\
\hline \multicolumn{5}{|l|}{$\mathrm{pN}$ stage } \\
\hline pNO & 1 & 1 & 1 & 1 \\
\hline $\mathrm{pN} 1-3$ & $1.934(1.441,2.595) ;<0.0001$ & $3.351(2.317,4.847) ;<0.0001$ & $3.726(2.606,5.328) ;<0.0001$ & $5.127(3.213,8.181) ;<0.0001$ \\
\hline \multicolumn{5}{|l|}{ Surgery } \\
\hline Partial & 1 & 1 & 1 & 1 \\
\hline Total & 1.226 (0.881, 1.708); 0.2269 & $1.357(0.965,1.909) ; 0.0796$ & $1.398(0.898,2.178) ; 0.1382$ & $1.455(0.919,2.302) ; 0.1093$ \\
\hline
\end{tabular}

associated with more advanced disease grade or stage.

In this study, the OS of patients with T2 stage disease was worse than that of those with T1 disease. Patients with T2 disease had a 1.388-fold increased risk of shorter OS, when compared with those with $\mathrm{T} 1$ disease. However, there was no significant statistical difference between $\mathrm{T}$ stages with respect to CSS. Zhu et al. (11) reported that $\mathrm{N}$ classification was significantly associated with patient survival, a finding which is consistent with that of our study. In our study, patients with N1-3 node status were at a 3.351-fold increased risk of shorter OS and a 5.127-fold increased risk of shorter CSS, when compared with those with N0 status.

Lont et al. (12) reported that patients with penile cancer associated with one or two positive lymph nodes had a 5-year survival rate of approximately 90\%. Pandey et al. (13) reported that three or four positive lymph nodes represented a cut-off point for poor survival in penile cancer. The number of lymph nodes removed during lymph node dissection is dependent upon both the quality of surgery and the pathology assessment (14). In this study, removal of four or more regional lymph nodes was associated with longer OS, when compared with the removal of one to three regional lymph nodes. Furthermore, the removal of four or more regional lymph nodes was also associated with longer CSS, when compared with the removal of fewer lymph nodes. We then performed a subgroup analysis in the PP and TP groups, after stratifying patients according to regional lymph node removal status. In this study, $\mathrm{PP}$ patients 
with regional lymph node removal had a longer CSS than PP patients without. However, there were no benefits in terms of OS. There were no statistically significant differences in OS and CSS between TP patients stratified according to their lymph node removal status. Zhu et al. (14) revealed that patients with extensive lymph node dissection had a better CSS, which is consistent with our study.

Nowadays, whether to perform inguinal lymphadenectomy in patients with high grade or invasive penile cancer remains controversial. Some researchers hold the view that the significant comorbidity of performing inguinal lymphadenectomy should not be ignored for the reported complication rate ranged from $14 \%$ to $37 \%$ based on previous researches $(15,16)$. Bouchot et al. (16) also demonstrated that the high risk of postoperative complications remain the major factor limiting the use of inguinal lymphadenectomy. Also, Spiess et al. (17) stated that regional lymphadenectomy is prone to complications. Nevertheless, Correa et al. (18) reported that patients with T1b-4 N0/x-1 who underwent inguinal lymphadenectomy possessed a better overall survival outcome than those who did not undergo inguinal lymphadenectomy. Stephenson et al. (19) also revealed that lymphadenectomy may be treated as a risk factor to be associated with a better survival outcome in patients with penile cancer accompanied with testis cancer. Plus, since 1988, researchers (20) have begun to find some ways to reduce the morbidity and to preserve the therapeutic effects. National Comprehensive Cancer Network (NCCN) and European Association of Urology (EAU) Guidelines strongly recommended that inguinal lymphadenectomy should be applied to any patient with high grade or invasive penile cancer, like $\mathrm{p} \mathrm{T} 1 \mathrm{~b}$ and $\mathrm{T} 4$. Those patients who present with no, or unilateral or low volume adenopathy (cN0-N1) should also offer inguinal lymphadenectomy. Besides, in selected candidates, patients with bilateral (cN2) or bulky (cN3) adenopathy should be applied to neoadjuvant chemotherapy followed by inguinal lymphadenectomy $(18,21,22)$. Also, staging and therapeutic intervention for invasive penile cancer are heavily based on the results of inguinal lymphadenectomy (23). We cannot evaluate the indication of inguinal lymphadenectomy by data extracted from the SEER database, for the indication of lymphadenectomy was not available in SEER database.

Kamel et al. (5) reported that the 5-year OS rates for $\mathrm{PP}$ and TP were $85 \%$ and $72 \%$, respectively, and that the 10 -year OS rates were $79 \%$ and $63 \%$, respectively. In our study, the 5-year OS rates for PP and TP were $59.02 \%$ and $53.55 \%$, respectively. These are lower than those reported by Kamel et al. (5) A potential reason for these differences could be that the proportion of N0 patients in both the PP (83.9\% for our study vs. $91.9 \%$ for Kamel et al.) and TP (82.2\% for our study vs. $87.4 \%$ for Kamel et al.) groups was lower in our study than in that of the former study. The 5-year CSS rates for PP and TP in our study were $76.68 \%$ and $68.99 \%$, respectively. In our study, there were no statistically significant differences in survival outcomes between the penile cancer patients of two surgical treatment groups. Kamel et al. (5) revealed that both PP and TP were not predictors of survival, a finding which is consistent with our study. Wen et al. (7) also demonstrated that there was no relationship between surgery type and CSS, a finding which is also consistent with our study.

It should be noted that our study has some limitations. First, the indication of lymphadenectomy was not indicated in this study due to the information of indication was not available in SEER database. Second, this is a retrospective study. Consequently, incomplete and missing information, including tumor size, could not be included in our analysis. Third, the small number of penile cancer patients included in the study may weaken the statistical power of the analysis of prognostic factors.

\section{Conclusions}

There were no significant differences in terms of OS and CSS between patients treated by PP or TP. T2 carcinoma was associated with shorter OS. Age and node stage N1-3 were associated with shorter OS and CSS. Removal of four or more regional lymph nodes was associated with longer OS and CSS.

\section{Acknowledgments}

Funding: None.

\section{Footnote}

Conflicts of Interest: All authors have completed the ICMJE uniform disclosure form (available at http://dx.doi. org/10.21037/tcr.2019.08.37). The authors have no conflicts of interest to declare.

Ethical Statement: The authors are accountable for all aspects of the work in ensuring that questions related to the accuracy or integrity of any part of the work are appropriately investigated and resolved. Information from the SEER database has been de-identified and informed 
consent is not required for its use.

Open Access Statement: This is an Open Access article distributed in accordance with the Creative Commons Attribution-NonCommercial-NoDerivs 4.0 International License (CC BY-NC-ND 4.0), which permits the noncommercial replication and distribution of the article with the strict proviso that no changes or edits are made and the original work is properly cited (including links to both the formal publication through the relevant DOI and the license). See: https://creativecommons.org/licenses/by-nc-nd/4.0/.

\section{References}

1. Salami SS, Montgomery JS. Surveillance strategies in the management of penile cancer. Transl Androl Urol 2017;6:868-73.

2. Siegel RL, Miller KD, Jemal A. Cancer Statistics, 2017. CA Cancer J Clin 2017;67:7-30.

3. McCormick B, Pettaway C. Insights Into the Management of Lymph Node-Positive Penile Cancer. JAMA Oncol 2018;4:650-1.

4. Veeratterapillay R, Teo L, Asterling S, et al. Oncologic Outcomes of Penile Cancer Treatment at a UK Supraregional Center. Urology 2015;85:1097-103.

5. Kamel MH, Tao J, Su J, et al. Survival outcomes of organ sparing surgery, partial penectomy, and total penectomy in pathological T1/T2 penile cancer: Report from the National Cancer Data Base. Urol Oncol 2018;36:82.e7-82.e15.

6. da Costa WH, Rosa de Oliveira RA, Santana TB, et al. Prognostic factors in patients with penile carcinoma and inguinal lymph node metastasis. Int J Urol 2015;22:669-73.

7. Wen S, Ren W, Xue B, et al. Prognostic factors in patients with penile cancer after surgical management. World J Urol 2018;36:435-40.

8. Sharma P, Ashouri K, Zargar-Shoshtari K, et al. Racial and economic disparities in the treatment of penile squamous cell carcinoma: Results from the National Cancer Database. Urol Oncol 2016;34:122.e9-15.

9. Thuret R, Sun M, Budaus L, et al. A population-based analysis of the effect of marital status on overall and cancerspecific mortality in patients with squamous cell carcinoma of the penis. Cancer Causes Control 2013;24:71-9.

10. Rippentrop JM, Joslyn SA, Konety BR. Squamous cell carcinoma of the penis: evaluation of data from the surveillance, epidemiology, and end results program. Cancer 2004;101:1357-63.

11. Zhu Y, Ye DW, Yao XD, et al. New N staging system of penile cancer provides a better reflection of prognosis. J Urol 2011;186:518-23.

12. Lont AP, Kroon BK, Gallee MP, et al. Pelvic lymph node dissection for penile carcinoma: extent of inguinal lymph node involvement as an indicator for pelvic lymph node involvement and survival. J Urol 2007;177:947-52; discussion 952.

13. Pandey D, Mahajan V, Kannan RR. Prognostic factors in node-positive carcinoma of the penis. J Surg Oncol 2006;93:133-8.

14. Zhu Y, Gu CY, Ye DW. Population-based assessment of the number of lymph nodes removed in the treatment of penile squamous cell carcinoma. Urol Int 2014;92:186-93.

15. Bevan-Thomas R, Slaton JW, Pettaway CA. Contemporary morbidity from lymphadenectomy for penile squamous cell carcinoma: the M.D. Anderson Cancer Center Experience. J Urol 2002;167:1638-42.

16. Bouchot O, Rigaud J, Maillet F, et al. Morbidity of inguinal lymphadenectomy for invasive penile carcinoma. Eur Urol 2004;45:761-5; discussion 765-6.

17. Spiess PE, Hernandez MS, Pettaway CA. Contemporary inguinal lymph node dissection: minimizing complications. World J Urol 2009;27:205-12.

18. Correa AF, Handorf E, Joshi SS, et al. Differences in Survival Associated with Performance of Lymph Node Dissection in Patients with Invasive Penile Cancer: Results from the National Cancer Database. J Urol 2018;199:1238-44.

19. Stephenson AJ, Sheinfeld J. Management of patients with low-stage nonseminomatous germ cell testicular cancer. Curr Treat Options Oncol 2005;6:367-77.

20. Catalona WJ. Modified inguinal lymphadenectomy for carcinoma of the penis with preservation of saphenous veins: technique and preliminary results. J Urol 1988;140:306-10.

21. Clark PE, Spiess PE, Agarwal N, et al. Penile cancer: Clinical Practice Guidelines in Oncology. J Natl Compr Canc Netw 2013;11:594-615.

22. Campbell RA, Slopnick EA, Ferry EK, et al. Disparity between pre-existing management of penile cancer and NCCN guidelines. Urol Oncol 2017;35:531.e9-531.e14.

23. Leijte JA, Kirrander P, Antonini N, et al. Recurrence patterns of squamous cell carcinoma of the penis: recommendations for follow-up based on a two-centre analysis of 700 patients. Eur Urol 2008;54:161-8.

Cite this article as: Zheng QL, Wu YP, Zhang ZP, Xu N. Partial penectomy or total penectomy for $\mathrm{T} 1$ and $\mathrm{T} 2$ squamous cell carcinoma of the penis? Transl Cancer Res 2019;8(5):17501755. doi: 10.21037/tcr.2019.08.37 